\title{
Promoting Self-Care Capabilities of Patients: Nurses' Roles
}

\author{
Ausanee Wanchai ${ }^{1 *}$ and Jane M Armer ${ }^{2}$ \\ ${ }^{1} R N$, PhD, Deputy Director for Academic Services and Research, Boromarajonani College of Nursing Buddhachinaraj, Thailand \\ ${ }^{2} R N$, PhD, FAAN, CLT, Professor at Sinclair School of Nursing, University of Missouri, Director, Nursing Research, Ellis Fischel Cancer Center, USA
}

Submission: April 20, 2018; Published: May 01, 2018

*Corresponding author: Ausanee Wanchai, Boromarajonani College of Nursing Buddhachinaraj, Muang, Phitsanulok, 65000- Thailand, Tel: 6655219041; Email: wausanee@hotmail.com

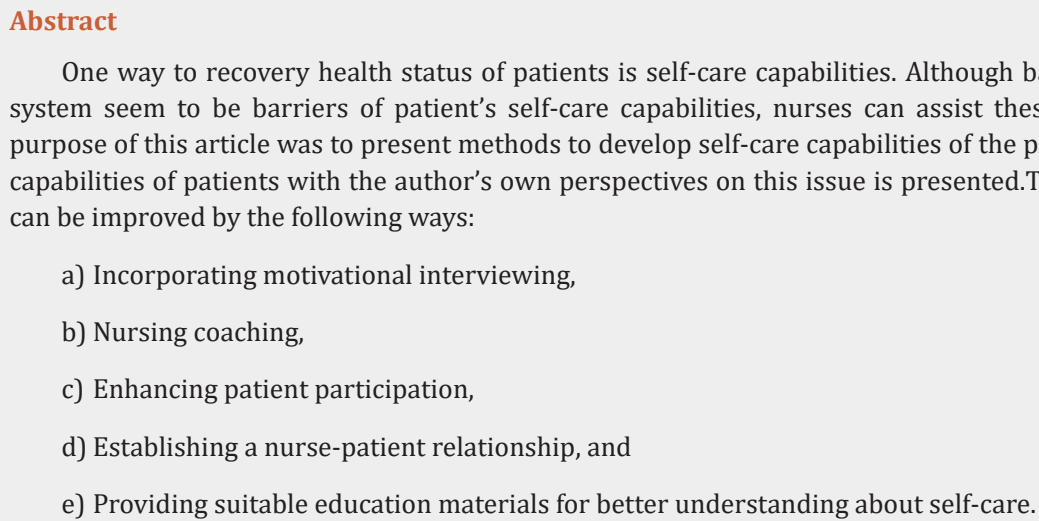
can be improved by the following ways:

a) Incorporating motivational interviewing,

b) Nursing coaching,

c) Enhancing patient participation,

d) Establishing a nurse-patient relationship, and

e) Providing suitable education materials for better understanding about self-care.

One way to recovery health status of patients is self-care capabilities. Although basic conditioning factors, such as age, gender, or family system seem to be barriers of patient's self-care capabilities, nurses can assist these patients to improve their self-care capabilities. The purpose of this article was to present methods to develop self-care capabilities of the patients.A brief overview of methods to develop self-care capabilities of patients with the author's own perspectives on this issue is presented.The results showed that self-care capabilities of patients

In conclusions, each method has its own appropriateness to be performed. Nurses need to justify and adapt one that is suitable with patient context.

Keywords: Self-care capabilities; coaching; motivation interviewing; patient participation; nurses and patient relationship; suitable education materials

\section{Introduction}

Capabilities stand for human powers that can be developed and properly referred to what people can do in knowing and meeting their own self-care requisites Orem [1,2]. However, developing self-care capabilities may or may not be operational at specific time. Insufficient knowledge about disease and symptom, ways of self-care along with hopelessness, and psychological problems limit patient's abilities for an effective self-care Siabani et al. [3]. Self-care capabilities also can be affected by basic conditioning factors, such as age, gender, developmental state, health state, socio cultural orientation, environmental factors, resource availability and adequacy, family system, health care system, and pattern of living Orem [1]; Denyes et al. [3]. Thus, after consideration of all enabling conditions, limitations, and basic conditioning factors, if a person's capabilities are inadequate to meet the therapeutic self-care demand, a self -care deficit exists Orem [1]. Then, nursing is needed to assist individuals to accomplish effective self-care. There are three types of nursing systems: a) Wholly compensatory systems, required for individuals who are unable to control and monitor their environment and process information;

b) Partly compensatory systems, designed for individuals who are unable to perform some (but not all)self-care activities; and

c) Supportive-educative systems, designed for persons who are able to perform or can and should learn to perform therapeutic self-care but cannot do without assistance Orem [1]. With regard to supportive-educative systems, Orem [1] stated that helping techniques in these situations include combinations of support, guidance, provision of a developmental environment, and teaching. In some situation, a patient may be able to perform care but needs guidance and support, while some situation, a patient may need teaching, and in some situation, a patient may need providing 
a developmental environment. Therefore, nurses can play important role as healthcare professionals who know how to assist persons to improve their self-care capabilities Allison [4]. The purpose of this article was to present methods to develop self-care capabilities of the patients. These include

a) Incorporating motivational interviewing,

b) Nursing coaching,

c) Enhancing patient participation, and

d) Establishing a nurse-patient relationship, as well as

e) Providing suitable education materials.

\section{Incorporating Motivational Interviewing}

Regarding motivation aspect, one strategy to motivate patients is motivational interviewing. Motivational interviewing is a clientcentered, directive counseling approach using communication skills aimed at promoting motivation in patients to change certain behaviors Borrelli etal. [5]; Miller [6]. A systematic review reported that motivational interviewing was effective on lifestyle behaviors, psychosocial outcomes, and symptom management Ekong et al. [7]; Spencer et al. [8]. Butterworth [9] suggested that this approach is helpful in situations where the patient is less motivated or less ready for change. There are four guiding principles in conducting motivational interviews, including; expressing empathy, developing discrepancies, rolling with resistance, and supporting self-efficacy. Levensky et al. [10] stated that to express empathy, nurse should communicate that she/he understands and accepts the patient's experience and patient's ambivalence about change. To develop discrepancies, nurse should enhance the patient to be aware of unhealthy behavior and his/her goals to motivate the patient to change. To roll with resistance, patients must try to find answer and solutions by themselves. Finally, to support selfefficacy, nurse should maintain and express to the patient a belief in the possibility of change, based on the patient's ability to choose and carry out a plan to change their behaviors. Levensky et al. [10] also suggested that to carry out these principles described above, four basic therapeutic skills should be performed, including: reflective listening, asking open-ended questions, affirming and supporting the patient during interaction, and summarizing statements that have been discussed. Previous studies suggested that motivational interviewing was an evidence-based approach that effectively helped patients to improve self-care agency Borrelli et al. [5]; Miller [6]; Levensky et al. [10]; Armer et al. [11]. Thus, motivational interviewing may be one method that can help patients to develop their self-care capabilities in engaging in their self-care.

\section{Nursing Coaching}

Individuals engage in self-care if certain enabling capabilities are available: valuing of one's health, self-care skills, and energy to perform self-care, as well as self-care knowledge Orem [1]; Zrínyi et al. [12]. Thus, another method to assist patients to develop selfcare capabilities is coaching as it is a useful model for promoting patients' capacity for taking charge of their growth processes and accepting accountability for choices made Hayes et al. [13]. Bennett et al. [14] defined coaching as a method of helping patients gain the knowledge, skills, and tools, as well as confidence to become active participants in their care so that they can reach their self-identified health goals. An appropriate coaching will help to motivate patients by considering new perspectives to start and maintain their changes that can contribute to the achieving goals Simmons et al. [15]. Effective coaching requires that the coach must practice interpersonal communication skills in order to facilitate client learning and development Hayes et al. [16]. Health coaching encompasses five principal roles, including:

a) Providing self-management support,

b) Bridging the gap between clinician and patient,

c) Helping patients navigate the health care system,

d) Offering emotional support, and

e) Serving as a continuity figure Bennett et al. [14].

A systematic review by Kivelä et al. [16] reported that coaching had positive effects on patients' physiological, behavioral and psychological conditions, and on their social life. In addition, statistically significant results showed better weight management, increased physical activity, and improved physical and mental health status.The coach model enables patients to take more responsibility for their own medical management. Thus, coaching may be an innovative method that can help patients to develop their self-care capabilities in engaging in their self-care.

\section{Enhancing Patient Participation}

Zrínyi et al. [12] stated that to promote self-care agency, patients should:

a) Be appropriately advised about health by nurses,

b) Be free to discuss health problem/needs with nurses,

c) Be received supportive and attentive nursing care.

In addition, to promote self-care capabilities, patients need to become involved as active members of healthcare team to regain some control over their situations Simmons [17] Thus, to achieve these goals, it is necessary to increase patient engagement in individual interactions with health care providers because patients and their families often bring important knowledge to their care if they are invited to do so Smith et al. [18]. A systematic review by Van Dam et al. [19] reported that such a method can be performed by focusing on patient behavior, such as assistantguided patient preparation for visits to doctors, empowering group education, group consultations, or automated telephone management. These methods showed more positive results on patient outcomes than those focused on provider behavior modification to change their consulting style into a more patientcenter one. Therefore, it indicates the importance of continuing to refine strategies for eliciting and integrating patient preferences 
into patient care, which in turn may help patients to develop their self-care capabilities in engaging in their self-care.

\section{Establishing a Nurse-Patient Relationship}

Orem [1] stated that to assist patients in enacting their expected health deviation self-care behaviors, a nurse should utilize effective interpersonal technologies to promote satisfying communication with the patient. This will result in positive relationship between nurse and patient, which in turn can improve self-care agency of the patient. Zrínyi et al. [12] reported that the better nurse-patient relationships, the greater level of self-care agency of the patient. Frank [20] suggested that while incorporating interpersonal technologies, nurses can provide education and support patients to understand their treatment regimen and to gain understanding as to how they can implement it effectively within the value system and resources they possess. With the effective interpersonal communication, it can foster patients' perception of being respected, valued, and appreciated, which can empower them to be more engage in selfcare. Continuing home visits by nurses also can help to establish a nurse-patient relationship, which in turn can enhance self-care agency of the patients Herber [21]. For example, Prenatal and infant/toddler home visitation by nurses is a promising means of reducing all-cause mortality among mothers and preventablecause mortality in their first-born children living in highly disadvantaged settings. Olds et al. [22] examined the effects of home visiting by nurses on maternal and child mortality. Nurses sought to improve the outcomes of pregnancy, children's health and development, and mothers' health and life-course with home visits beginning during pregnancy and continuing through child age 2 years.The results showed that prenatal and infant home visitation by nurses was a promising means of reducing all-cause mortality among mothers and preventable-cause mortality in their first-born children living in highly disadvantaged settings.Thus, establishing a nurse-patient relationship should be considered as one way to help patients to develop their self-care capabilities in engaging in their self-care.

\section{Providing Suitable Education Materials}

Orem [1] stated that self-care agency can be developed through process of learning. However, limitation in one's ability to read and comprehend written patient education materials can interfere with one's ability to judge what should be done in certain situations or in personal decision-making about self-care. Accordingly, nurses should guide the patients in selection and use of written patient education materials that are suited to their capabilities Wilson [23]. Graham and Brookey [24] suggested that to be clearer and better understanding, written materials should be created in a patient-friendly manner. This means using simple words, short sentences in bulleted format, and lots of white space. In addition, medical jargon should be avoided and simple pictures should be used. Finally, emphasis should be on what the patient should do, while unnecessary information should be avoided. Wilson et al. [23] suggested that it is health care providers' responsibility to evaluate whether written patient education materials are appropriate for the patient. They suggested that health care providers should consider if the material is congruent with patient factors of age, gender, education, socio cultural orientation, socioeconomic status, learning needs, cognitive abilities, reading and comprehensive skills, attitude and beliefs about health practices, and knowledge about his/her condition. In addition, material should be evaluated whether it is attractive, whether the text is written in active or conversational voice, and whether there is ample white space. Using appropriate educational materials to communicate with patients, particularly those with low-literacy, will influence their decisions to participate in their own care as the barrier to health care such unreadable materials are resolved Wilson et al. [23]. Therefore, evaluation of patient educational materials should be performed.

\section{Conclusion}

In conclusion, there are various methods can be used to develop self-care capabilities of patients such as motivational interviewing, nursing coaching, establishing a nurse-patient relationship, enhancing patient participation, or providing suitable education materials. However, one must realize that only one time performing of these methods does not necessarily indicate developed self-care agency. Therefore, such a supportiveeducative intervention must be maintained for as long as necessary.

\section{References}

1. Orem DE (2001) Nursing concepts of practice (6 ${ }^{\text {th }}$ edn) St Louis: Mosby.

2. Siabani S, Leeder SR, Davidson PM (2013) Barriers and facilitators to self care in chronic heart failure: a meta synthesis of qualitative studies. Springer Plus 2: 320.

3. Denyes MJ, Orem DE, Soz Wiss GB (2001) Self care: A foundational science. Nursing Science Quarterly 14: 48-54.

4. Allison SE (2007) Self care requirements for activity and rest: An Orem nursing focus. Nursing Science Quarterly 20: 68-76.

5. Borrelli B, Riekert KA, Weinstein A, Rathier L (2007) Brief motivational interviewing as a clinical strategy to promote asthma medication adherence. Journal of Allergy and Clinical Immunology 120: 10231030.

6. Miller NH (2010) Motivational interviewing as a prelude to coaching in healthcare settings. Journal of Cardiovascular Nursing 25: 247-251.

7. Ekong G, Kavookjian J (2016) Motivational interviewing and outcomes in adults with type 2 diabetes: A systematic review. Patient Education and Counseling 99: 944-952.

8. Spencer JC, Wheeler SB (2016) A systematic review of Motivational Interviewing interventions in cancer patients and survivors. Patient Education and Counseling 99: 1099-1105.

9. Butterworth S (2010) Health coaching strategies to improve patient centered outcomes. Journal of the American Osteopatic Association 110: eS12-eS14.

10. Levensky ER, Forcehimes A, O Donohue WT, Beitz K (2007) Motivational interviewing: An evidence-based approach to counseling helps patients follow treatment recommendations. American Journal of Nursing 107: 50-58. 
11. Armer JM, Shook RP, Schneider MK, Brooks CW, Peterson J, et al. (2009) Enhancing supportive educative nursing systems to reduce risk of post breast cancer lymphedema. Self Care, Dependent Care \& Nursing 17: 6-15.

12. Zrínyi M, Zékányné RI (2007) Does self care agency change between hospital admission and discharge? An Orem-based investigation. International Nursing Review 54: 256-262.

13. Hayes E, Kalmakis KA (2007) From the sidelines: Coaching as a nurse practitioner strategy for improving health outcomes. Journal of the American Academy of Nurse Practitioners 19: 555-562.

14. Bennett HD, Coleman EA, Parry C, Bodenheimer T, Chen EH (2010) Health coaching for patients with chronic illness. Family Practice Management 17(5): 24-29.

15. Simmons LA, Wolever RQ (2013) Integrative Health Coaching and Motivational interviewing: Synergistic Approaches to Behavior Change in Healthcare. Global Advances in Health and Medicine 2(4): 28-35.

16. Kivelä K, Elo S, Kyngäs H, Kääriäinen M (2014) The effects of health coaching on adult patients with chronic diseases: A systematic review. Patient Education and Counseling 97(2):147-157.

17. Simmons L (2009) Dorthea Orems Self Care Theory as related to nursing practice in hemodialysis. Nephrology Nursing Journal 36(4): 419-421.

his work is licensed under Creative Commons Attribution 4.0 License

DOI: $10.19080 / J O J N H C$ 2018.07555719
18. Smith M, Saunders R, Stuckhardt L, McGinnis JM (2012) Best care at lower cost: The path to continuously learning health care in America.

19. Van Dam HA, van der Horst F, van den Borne B, Ryckman R, Crebolder $\mathrm{H}$ (2003) Provider-patient interaction in diabetes care: effects on patient self-care and outcomes: A systematic review Patient Education and Counseling 51: 17-28.

20. Frank DI (2003) Elderly clients perceptions of communication with their health care provider and its relation to health deviation self care behaviors. Self Care Dependent Care and Nursing 11: 15-30.

21. Herber OR, Schnepp W, Rieger MA (2008) Developing a nurse led education program to enhance self-care agency in leg ulcer patients. Nursing Science Quarterly 21: 150-155.

22. Olds DL, Kitzman H, Knudtson MD, Anson E, Smith JA, Cole R (2014) Effect of Home Visiting by Nurses on Maternal and Child Mortality: Results of a 2 Decade Follow up of a Randomized Clinical Trial. JAMA Pediatrics 168(9): 800-806.

23. Wilson FL, Mood DW, Risk J, Kershaw T (2003) Evaluation of education materials using Orem's Self Care Deficit Theory. Nursing Science Quarterly 16: 68-76.

24. Graham S, Brookey J (2008) Do Patients Understand? The Permanente Journal 12(3): 67-69.

\section{Your next submission with Juniper Publishers will reach you the below assets}

- Quality Editorial service

- Swift Peer Review

- Reprints availability

- E-prints Service

- Manuscript Podcast for convenient understanding

- Global attainment for your research

- Manuscript accessibility in different formats

( Pdf, E-pub, Full Text, Audio)

- Unceasing customer service

Track the below URL for one-step submission https://juniperpublishers.com/online-submission.php 